This report was prepared as an account of work sponsured by an agency of the United Sintes Government. Neither the United States Government nor any agency thereof, nor any of their employees, makes any warranty, express or implied, or assumes any legal liability or responsibility for the accuracy, completeness, or usefulness of any information, apparatus, product, or process disclosed, or represents that its use would not infringe privately owned rights. Reference herein to any specific commercial product. process, or service by trade name, trademark. manufacturer, or otherwise does not necessarily corstitute or imply its endorsement, recommendation, or favoring by the United States Government of any agency thereof. The ricvis and opinions of authors expressed herein do not necessarily state or reflect those of the United States Government or any agency thereof.

\title{
Release Rates in a Salt Repository by Diffusion
}

\author{
Y. Hwang, W. W.-L. Lee, P. L. Chambre, and T. H. Pigford \\ Department of Nuclear Engineering \\ University of California \\ and
}

Earth Sciences Division, Lawrence Berkeley Laboratory

1 Cyclotron Road

Berkeley, CA 94720

\section{September 1988}

Work supported in part by the Director, Office of Civilian Radioactive Waste Management, Office of Systems Integration and Regulations, Licensing and Compllance Division, of the U.S. Department of Energy via contract DE-ACO3-

76 SF00098. 
The authors invite comments and would appreciate being notified of any errors in the report.

T. H. Pigford Department of Nuclear Engineering University of California Berkeley, CA 94720 


\section{Contents}

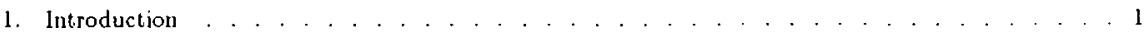

2. Analysis . . . . . . . . . . . . . . . . . . . . . . . . 1

2.1 Low-Solubility Species . . . . . . . . . . . . . . . . . . . . . . . . . . 2

2.1 Readily Soluble Species . . . . . . . . . . . . . . . . . . . . . . . . . 4

3. Numerical Illustrations . . . . . . . . . . . . . . . . . . . . . . . . . . . . . . . 5

4. Comparison with the Environmental Assessments Analysis . . . . . . . . . . . . . . . . . . 8

5. Conclusions. . . . . . . . . . . . . . . . . . . . . . . . . . . . . . . . . . 12

6. References .. . . . . . . . . . . . . . . . . . . . . . . . . 12

\section{List of Figures}

Figure 1. Fractional Release Rates of Low-solubility Species . . . . . . . . . . . . . . . . . . . 7

i igure 2. Fractional Release Rates of Soluble Species _. . . . . . . . . . . . . . . . . . . . . g

Figure 3. Fractional Release Rates of of U-234 at Different Positions . . . . . . . . . . . . . . . 10

Figure 4. Comparison of Current Analysis with McNulty et al. for U-238 . . . . . . . . . . . . 13 


\section{Introduction}

In 1985 Pigford and Chambré proposed ${ }^{1}$ a method of predicting radionuclide release rates in a salt repository of high-level nuclear waste, based on mass-transfer analysis. Recognizing that within a few years after the emplacement of heat-emitting waste packages salt creep is likely to close the air gap between a waste container and the borehole wall, it was proposed that thereafter release rate of dissolved species from the waste solid is likely to be governed by mass transfer into brine in grain boundaries in the surrounding salt and in intersecting interbeds of other rock. Because of the low expected migration velocities of brine in the consolidated salt, mass transfer dominated diffusion was a likely possiblity. If so, nuany of the mass-transfer analyses previously developed could be adapted for predicting release rates in a salt repository.

Subsequent analyses of creep closure and consolidation by Brandshaug ${ }^{2}$ show that consolidation is expected within a few years after emplacement.

In a recent analysis ${ }^{3,4}$ we predicted extremely small brine migration velocities after emplacenent of waste packages. Therefore it is expected that mass transfer of radioactive species dissolved in the brine is likely to be controlled by molecular diffusion.

Here we apply the analytic solutions for the rate of diffusive mass transfer of dissolved species through a riorous medium to predict radionuclide release rates from waste packages in salt. This analysis shows that for the parameter values selected here, and for containment times of over 300 ycars, release rates from individual waste packages in sait can meet the U. S. Nuclear Regulatory Commission's (USNRC) performance objective for the engineered barrier system. ${ }^{5}$ If many waste packages are actually exposed to brine much sooner than 300 years after emplacement, it will be difficult to meet the release rate for ${ }^{137} \mathrm{Cs}$, calculated from the USNRC regulation. ${ }^{5,6}$

In this report we present the analytic solutions and some numerical illustrations of the molecular diffusion analysis. We also compare the results with a different type of diffusion analysis ${ }^{7}$ in the Environmental Assessments ${ }^{8,9,10}$ for the potential repository sites in salt.

\section{Analysis}

The waste container is conservatively assumed to have failed during consolidation or shortly thereafter, so that brine at the waste surface begins to dissolve the spent-fuel waste and its radioactive inventory. The dissolution rate of spent fuel is assumed to be limited by uranium solubility and diffusion into brine contained in the grain boundaries of the surrounding salt. Actinides and other low-solubility constituents are assumed to be released congruently. Iodine, cesium, and and other readily-soluble constituents are assumed to dissolve instantaneously when brine enters failed waste packages. Their release rate into surrounding salt is alsc limited by diffusion. 
To predict release rates from the fuel matrix we assume a waste package surrounded by consolicated salt. At $t=0$ the container and fuel cladding are assumed to disappear, allowing stagnant brine to contact the spent fuel.

In previous papers, we presented results for the dissolution and transport of low-solubility species and readily soluble species in a diffusive-advective enviconment. ${ }^{11,12}$ In this section we will state the results without proof.

\subsection{Low-Solubillty Specie:}

For a spherical-equivalent waste solid without a metallic container in an infinite porous medium, the conservation of mass for dissolution and transport is

$$
K \frac{\partial N(r, t)}{\partial t}=D \frac{1}{r^{2}} \frac{\partial}{\partial r}\left(r^{2} \frac{\partial N(r, t)}{\partial r}\right)-\lambda K N(r, t), \quad r>r_{0}, t>0
$$

where $N(r, t)$ is the species concentration $\left[\mathrm{M} / \mathrm{L}^{3}\right]$,

$K$ is the species retardation coefficient $[-]$,

$\lambda$ is the species decay constant $\left[\mathrm{t}^{-1}\right]$,

$D$ is the species diffusion coefficient $\left[\mathbf{M}^{2} / \mathbf{t}\right]$,

$r$ is the spatial variable, $[\mathbf{L}]$,

$r_{0}$ is the radius of the waste sphere, $[L]$, and

$t$ is the time variable, $[t]$.

The initial and boundary conditions are

$$
\begin{array}{ll}
N(r, 0)=0, & r>r_{o} \\
N\left(r_{o}, t\right)=N^{*}, & t \geq 0 \\
N(\infty, t)=0, & t \geq 0
\end{array}
$$

where $N^{*}$ is the saturation concentration of the species, $\left[M / L^{3}\right]$.

The solution to (1) through (4) is ${ }^{13}$

$N(r, t)=\frac{N^{*} r_{o}}{2 r}\left\{e^{\left(r-r_{0}\right) \sqrt{K \lambda / D}} \operatorname{erfc}\left(\frac{\left(r-r_{o}\right)}{2} \sqrt{K / D t}+\sqrt{\lambda t}\right)\right.$ 
$\left.+e^{-\left(r-r_{a}\right) \sqrt{K \lambda / D}} \operatorname{erfc}\left(\frac{\left(r-r_{o}\right)}{2} \sqrt{K / D t}+\sqrt{\lambda t}\right)\right\}, \quad r>r_{o}, \quad \dot{t}>0$

The mass release rate of the species from the waste solid surface into the surrounding salt is

$$
\dot{M}(t)=4 \pi r_{o}^{2}\left(-\epsilon D \frac{\partial N\left(r_{0}, t\right)}{\partial r}\right), \quad t>0
$$

If we assume the low-solubility species is released congruently with the waste matrix, and the matrix leach time is $T_{m}$, then the mass release rate from the waste surface is

$$
\dot{M}(t)=4 \pi r_{o} N^{*} D \epsilon\left(1+\sqrt{\frac{K_{m} r_{o}^{2}}{\pi D t}}\right)\left(h(t)-h\left(t-T_{m}\right)\right), \quad t>0
$$

where $K_{m}$ is the retardation coefficient of the matrix. The leach time $T_{m}$ is obtained by solving

$$
T_{\mathrm{m}}=\frac{M_{\mathrm{m}}}{A}+\frac{B^{2}-B \sqrt{B^{2}+4 A M_{m}}}{2 A^{2}}
$$

where $M_{m}$ is the initial inventory of the matrix, [M],

$A=4 \pi \epsilon r_{0} D N^{*}$,

$B=8 \pi N^{*} r_{0}^{2} \sqrt{\pi D K_{m}}$ เnd

$M_{m}=\int_{0}^{T_{m}} \dot{M}\left(t^{\prime}\right) d t^{\prime}$

The fractional release rate into the surrounding salt, based on the 1000 -year inventory $M^{\circ}$ as required by the USNRC, is

$$
f=\frac{\dot{M}(t)}{M^{0}}
$$

Then,

$$
f=\frac{4 \pi r_{0} N^{*} D \epsilon}{M^{0}}\left(1+\sqrt{\frac{K_{m} r_{0}^{2}}{\pi D t}}\right)\left(h(t)-h\left(t-T_{m}\right)\right), \quad t>0
$$

We use (9) to compute fractional release rates for low-solubility species.

It is sometimes interesting to see the mass transfer rates at some distance into the salt. For long-lived nuclides we can assume $\lambda \rightarrow 0$, and (5) reduces to

$$
N(r, t)=\frac{N^{*} r_{o}}{r} \operatorname{erfc}\left\{\frac{\left(r-r_{o}\right)}{2} \sqrt{K / D t}\right\}, \quad r>r_{o}, \quad \iota>0
$$

Then the gradient at any point $r$ within the salt is

$$
\frac{\partial N(\boldsymbol{r}, t)}{\partial r}=\frac{-N^{*} r_{0}}{r^{2}} \operatorname{erfc}\left\{\frac{\left(r-r_{0}\right)}{2} \sqrt{K / D t}\right\}-\frac{N^{*} r_{0}}{r} \frac{1}{\sqrt{\pi}} \sqrt{K / D t} \exp \left\{\frac{-K^{\prime}\left(r-r_{0}\right)^{2}}{4 D t}\right\}
$$


and the local fractional release rate at that point is

$$
\begin{aligned}
& f=\frac{4 \pi r^{2}}{M^{0}}\left(-\varepsilon D \frac{\partial N(r, t)}{\partial r}\right) \\
& =\frac{4 \pi N^{*} r_{o} \varepsilon D}{M^{0}} \operatorname{erfc}\left\{\frac{\left(r-r_{0}\right)}{2} \sqrt{K / D t}\right\}-\frac{N^{*} r_{o}}{r} \frac{1}{\sqrt{\pi}} \sqrt{K / D t} \exp \left(\frac{K\left(r-r_{0}\right)^{2}}{4 D t}\right)
\end{aligned}
$$

\subsection{Readily Soluble Species}

For species that dissolve readily in brine, we assume that there are voids or gaps in the waste package that fill with brine when the waste package fails. At $t=0$ a specified amount dissolves instantaneously into a water-filled gap or void space in contact with the porous rock. Linear geometry is used with the waste/salt interface located $a$ away from the waste surface. The dissolved species migrate into the porsus material under the influence of a concentration gradient. It is expected that advective transport in the pore liquid will be relative!y small, so that the governing equation for this migration is

$$
K \frac{\partial N(x, t)}{\partial t}=D \frac{\partial^{2} N(x, t)}{\partial x^{2}}-\lambda K N(x, t), \quad x>a, \quad t>0
$$

where $N(x, t)$ is the species concentration in the pore liquia,

$K$ is the retardation coefficient, and

$D$ is the diffusion coefficient.

The initial and boundary conditions are

$$
\begin{aligned}
N(x, 0) & =0, \quad x>a \\
N(a, t)=c(t), & t \geq 0 \\
N(\infty, t)=0, & t \geq 0
\end{aligned}
$$

where $c(t)$ is the time-dependent of the soluble species in the water in the gap or void water. Because this void space is small, we assume that it is well-mixed and that $c(t)$ is not position-dependent. To solve for $c(t)$, the mass balance in the void is

$$
V \frac{d c(t)}{d t}=\dot{m}_{f}(t)-\dot{m}(t)-\lambda V c(t), \quad t>0
$$

where $\dot{m}_{f}(t)$ is the mass rate of dissolution of the species from the waste form into the void water, $\dot{m}$ is the mass rate of diffusion into the rock, and $V$ is the volume of the void water. 
To solve (17), we use the initial condition

$$
c(0)=c^{\circ}
$$

where $c^{\circ}$ is the initial concentration of the species in the void water.

The solution below was obtained by Chambré. ${ }^{13}$

$$
c(t)=\mu^{\circ} e^{-\lambda t} \mathrm{~F}\left(\beta^{2} t\right)+\frac{1}{V} \int_{0}^{t} \dot{m}_{f}(t-\tau) e^{-\lambda \tau} \mathrm{F}\left(\beta^{2} \tau\right) d \tau, \quad t>0
$$

where

$$
\mathrm{F}\left(\beta^{2} t\right) \equiv e^{\beta^{3}} \operatorname{erfc} \sqrt{\beta^{2} t}
$$

and

$$
\beta \equiv \sqrt{D K \epsilon^{2} / a^{2}}
$$

The mass rate of diffusion of the dissolved species into the salt is

$$
\dot{m}(t)=-\left.S D \epsilon \frac{\partial N(x, t)}{\partial x}\right|_{z=a .} \quad t>0
$$

where $S$ is the surface area of the interface between tire void spacc and the salt. If the void water extends from $x=0$ to $x=a$ then $S \equiv V / a$. Using (18) the solution to (19) is

$$
\dot{m}(t)=N^{\circ} \beta V e^{-\lambda t}\left\{\frac{1}{\sqrt{\pi t}}-\beta \mathbf{F}\left(\beta^{2} t\right)\right\}+\beta \int_{0}^{t} \dot{m}_{f}(t-\tau) e^{-\lambda \tau}\left\{\frac{1}{\sqrt{\pi \tau}}-\beta \mathrm{F}\left(\beta^{2} \tau\right)\right\} d \tau, \quad t>0
$$

The fractional release rate of a soluble species whose initial inventory is $M_{0}$, denoted $f^{\prime}$, is

$$
f^{\prime}(t)=\frac{N^{0} \beta V e^{-\lambda t}}{M_{0}}\left\{\frac{1}{\sqrt{\pi t}}-\beta \mathrm{F}\left(\beta^{2} t\right)\right\}+\beta \int_{0}^{t} \dot{m}_{f}(t-\tau) e^{-\lambda \tau}\left\{\frac{1}{\sqrt{\pi \tau}}-\beta \mathrm{F}\left(\beta^{2} \tau\right)\right\} d \tau, \quad t>0
$$

Eq. (21) is used to compute fractional release rates for soluble species. The initial concentration $c^{\circ}$ can be calculated by specifying the void water volume and the amount of the species in the waste that is available for rapid dissolution when water fills the void space.

\section{Numerical Illustration}

In this section we illustrate the above results using conditions typical of a nuclear waste repository in salt. Uur reference waste package is the reference waste package for pressurized water reactor spent fuel used in the Environmental Assessments. ${ }^{8,9,10}$ The dimensions and quantities of variou: nuclides are obtained therefrom.

For the release of low-solubility nuclides from a spherical waste solid, we formed a sphere of the same surface area as the cylindricai waste in the Environmental Assessments. 
The inventory of various nuclides as a function of time is taken from the official OCRWM data source, Ref. 14.

Table I lists dimensions of the waste package. Table II lists properties of the salt, from McTigue ${ }^{15}$ Tàule III lists characteristics of the nuclides used in the calculations. In Table III the nuclide inventories are from Ref. 14. The retardation coefficients are from estimates by Krauskopf. ${ }^{16}$ The solubility of uranium is from Krauskop $\mathrm{f}^{16}$ and Cloke ${ }^{17}$. The decay coefficients are taken from Browne and Firestone. ${ }^{18}$ All five nuclides in Table III are "low-inventory" nuclides in the USNRC regulation and their allowable release rate limits have been calculated according to a clarification letter from the USNRC. ${ }^{19}$

Table I. Waste Package Dimensions, Spent Fuel from Pressurized Water Reactors

\begin{tabular}{|l|c|c|}
\hline Height & $(\mathrm{m})$ & 3.68 \\
\hline Radius & $(\mathrm{m})$ & 0.285 \\
\hline Radius of Equivalent Sphere & $(\mathrm{m})$ & 0.752 \\
\hline Thickness of Gap & $(\mathrm{cm})$ & 7.0 \\
\hline Volume of Gap & $\left(\mathrm{m}^{3}\right)$ & 0.45 \\
\hline
\end{tabular}

Table II. Salt Properties

\begin{tabular}{|l|l|l|}
\hline Diffusion Coefficient & $\mathrm{cm}^{2} / \mathrm{s}$ & $10^{-7}$ \\
\hline Porosity & & 0.001 \\
\hline
\end{tabular}

Table III. Characteristics of the Nuclides Studied

\begin{tabular}{|l|c|c|c|c|c|}
\hline & Cs-135 & Cs-137 & I-129 & Np-237 & U-234 \\
\hline Retardation Coefficient & 10 & 10 & 1 & 20 & 20 \\
\hline Decay Constant $\left(\mathrm{a}^{-1}\right)$ & $2.3 \times 10^{-7}$ & $2.3 \times 10^{-2}$ & $4.1 \times 10^{-8}$ & $3.2 \times 10^{-7}$ & $2.8 \times 10^{-6}$ \\
\hline Solubility $\left(\mathrm{g} / \mathrm{m}^{3}\right)$ & $*$ & $*$ & $*$ & $1 \times 10^{-3}$ or 50 & $1 \times 10^{-3}$ or 50 \\
\hline Initial Inventory Per Package $(\mathrm{g})$ & $1.38 \times 10^{3}$ & $5.35 \times 10^{3}$ & $8.21 \times 10^{2}$ & $2.04 \times 10^{3}$ & $9.09 \times 10^{2}$ \\
\hline Initial Nuclide Conc. in Waste $\left(\mathrm{g} / \mathrm{m}^{3}\right)$ & $1.47 \times 10^{3}$ & $5.70 \times 10^{3}$ & $8.74 \times 10^{2}$ & $2.17 \times 10^{3}$ & $9.68 \times 10^{2}$ \\
\hline Initial Nuclide Conc. in Gap $\left(\mathrm{g} / \mathrm{m}^{3}\right)$ & $3.07 \times 10^{1}$ & $1.19 \times 10^{2}$ & $1.82 \times 10^{1}$ & $*$ & $*$ \\
\hline USNRC Release Rate Limit $\left(\mathrm{a}^{-1}\right)$ & $5.0 \times 10^{-5}$ & $2.0 \times 10^{-10}$ & $5.5 \times 10^{-4}$ & $1.7 \times 10^{-5}$ & $2.0 \times 10^{-5}$ \\
\hline
\end{tabular}

* Not used in these calculations.

The fractional release rates of ${ }^{234} \mathrm{U}$ and ${ }^{237} \mathrm{~Np}$ are shown in Figure 1 for two values of the solubility of the uranium matrix. First, a value for the solubility of uranium of $1 \times 10^{-3} \mathrm{~g} / \mathrm{m}^{3}$ is used, based on estimates by Krauskopf for mildly reducing conditions. ${ }^{16}$ Using this low solubility, the fractional release 


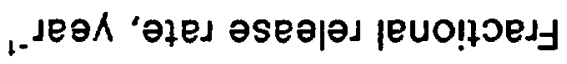

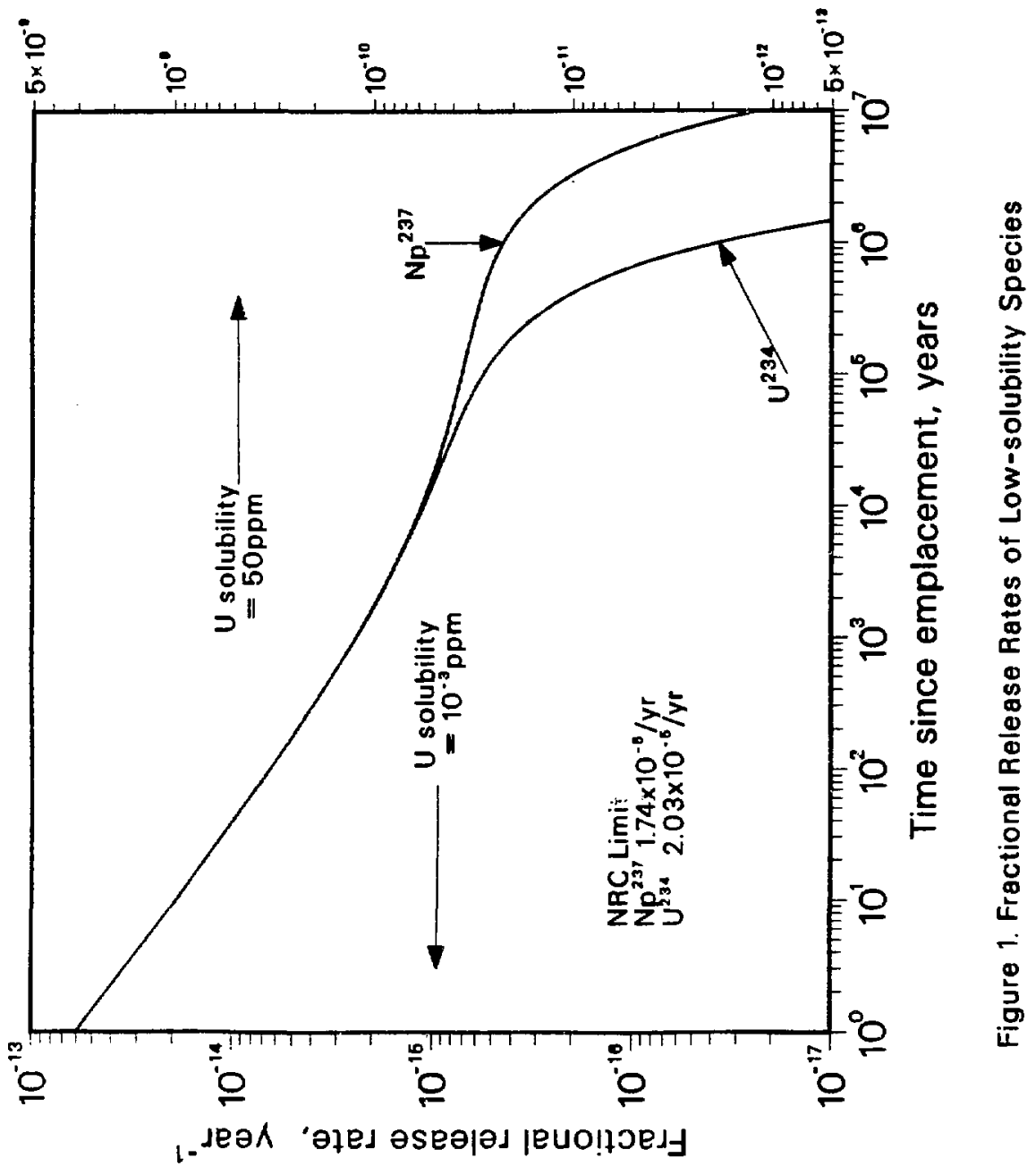


rates of these actinides are very low, well below the $\mathbf{U}$. S. Nuclear Regulatory Commission's release rate limit for the engineered barrier system, if that requirement is to apply at the interface between $a$ bare waste anj the salt. Near the waste, however, radiolysis might create a locally oxidizing region and could result in a uranium solubility as high as $50 \mathrm{~g} / \mathrm{m}^{3}$. The release rates using this solubility are shown on the right hand scale. Although higher by over four orders of magnitude, these release rates are still below the release rate limits for the engineered barrier system.

The fractional release rates for soluble species are shown in Figure 2, normalized here to initial insentories and assuming that waste is exposed to brine shortly after emplacement. It is assumed that one percent of the total inventory of cesium and iodine is present as readily soluble species in the fuel. The dissolution of of cesium and iodine species by congruent dissolution from the waste matrix is also calculated but is much

smaller than the contribution from readily soluble material, and has been neglecied in Figure 2.

The release rates of ${ }^{135} \mathrm{Cs}$ and ${ }^{129} \mathrm{I}$ are below the calculated release rate imits at all times shown in Figure 2. The calculated limit for ${ }^{137} \mathrm{C} \varepsilon$ is exceeded for some 300 years, if no waste container is present. $A$ container with a life of 300 years will allow sufficient decay time for the calculated limit for ${ }^{137} \mathrm{Cs}$ to be met.

Figure 3 shows the fractional release rate of ${ }^{224} \mathrm{U}$ from a solubility-limited waste ruatrix as a function of distance from the waste surface and for various times after the beginning of dissolution. For the diffusion parameters assumed here the dissolved uranium penetrates just more than one meter into the surrounding salt in 10,000 years.

\section{Comparison with the Environmental Assessments Analysis}

An analysis by McNulty, Bloom and Raines ${ }^{4}$ of diftusive transport in a salt repository is in the Environmental Assessmentss ${ }^{8,9,10}$ for potential repository sites in salt. Here we summarize that, anaiysis and compare its results with those calculated from our analysis presented above. Most of this summary is tak'n directly from McNulty, Bloom and Raines. ${ }^{4}$ A few variable names have been substiluted for nomencitture consistency.

The analysis assumes that brine in salt diffuses through salı :nder a "diffusion-like" mechanism. McNulty, Bloom and Raines made the following assumptions

- The process begins after brine has migrated into an assumed open borehoie around a single waste package due to the thermal gradient. ${ }^{20}$

- At $t=0$ all the radioactivity in the repository is dissulved into the brine, and the entire repnsitory becomes an instantanous planar source.

- At $t=0$ the brine is assumed to migrate vertically from the repository.

- Waste form or matrix offers no resirtance to nuclide dissolution.

- The inventories of nuclides used are their maximum in $10^{f}$ years. 


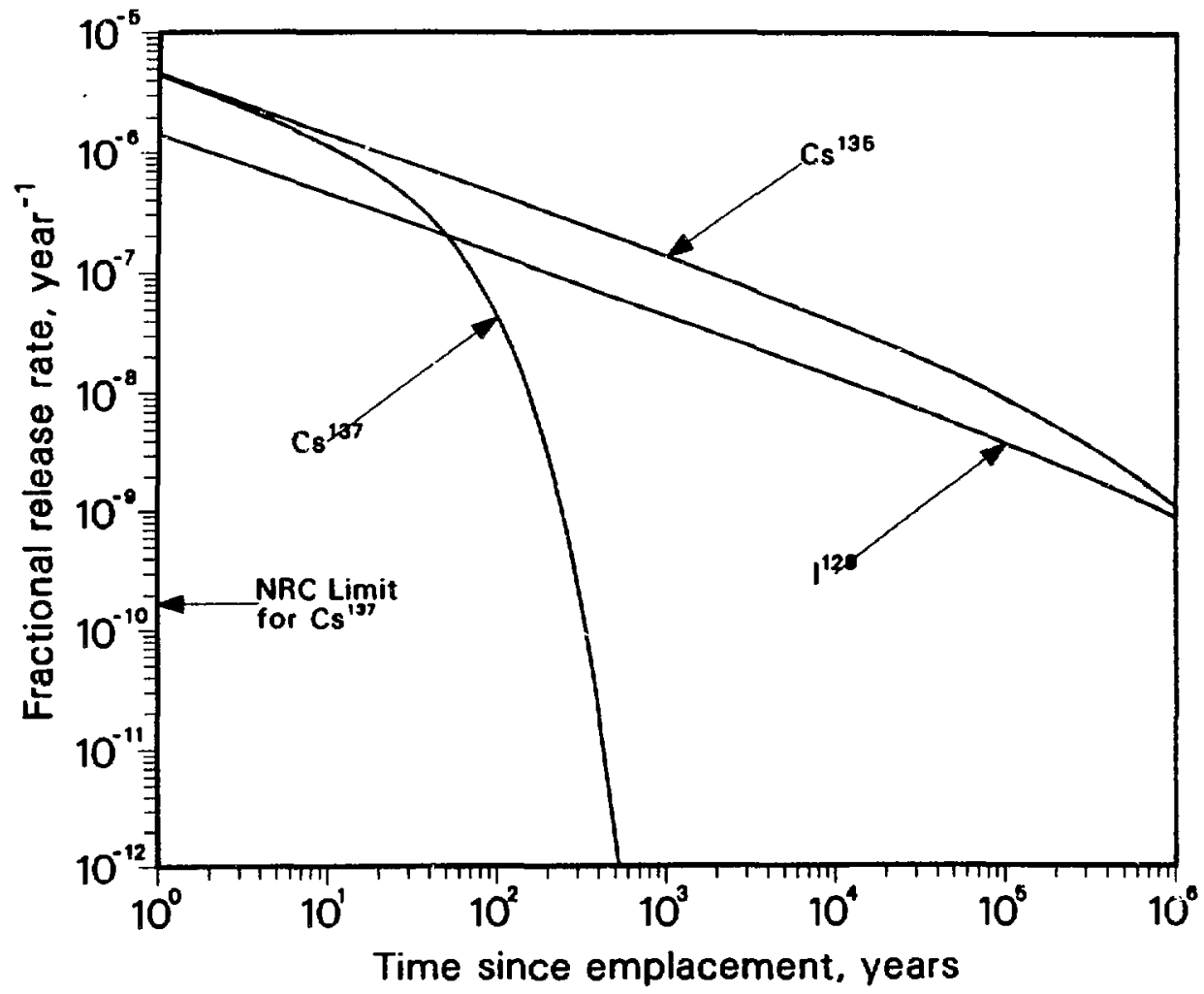

Figure 2. Fractional Release Rates of Soluble Nuclides 


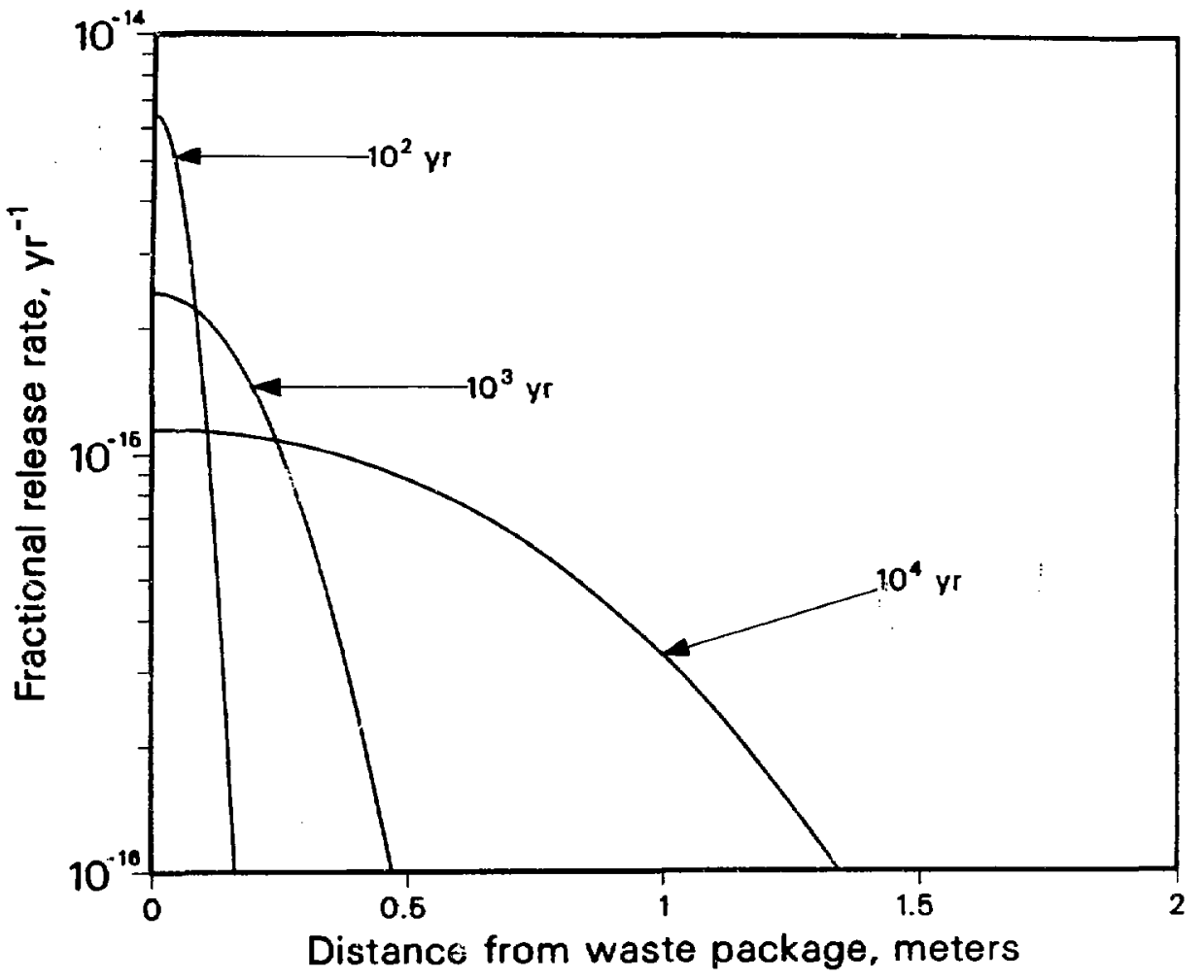

Figure 3. Fractional Release Rate of U-234 at Different Positions 
The equation for the movement of brine in salt is

$$
\frac{\partial C}{\partial t}=D\left(\frac{\partial^{2} C}{\partial X^{2}}+\frac{\partial^{2} C}{\partial Y^{2}}+\frac{\partial^{2} C}{\partial Z^{2}}\right)
$$

where $C$ is the brine concentration in salt $\left[\mathrm{L}^{3}\right.$ water $/ \mathrm{L}^{3}$ salt $]$, and $X, Y, Z$ are the spatial variables $[\mathrm{L}]$.

For an instantaneous plane source, the solution is

$$
C=\frac{0.5 B_{o}}{A \sqrt{\pi D t}} e^{-Z^{2} / 4 D t}
$$

where $B_{0}$ is the initial volume of brine around a waste package $\left[\mathrm{L}^{3}\right]_{;}$, and $A$ is the horizontal surface area above or below each waste package through which brine will move $\left[\mathrm{L}^{2}\right]$.

The brine flow rate (volumetric) past any location is

$$
q=-A D \frac{\partial C}{\partial \bar{Z}}
$$

Therefore

$$
q=0.25 B_{o} Z \frac{1}{\sqrt{\pi D t^{3}}} e^{-Z^{3} / 4 D t}
$$

To get the release rate of radionuclides, a factor $g$ is used

$$
g= \begin{cases}\left(I_{o} / B_{0}\right) e^{-\lambda t}, & \text { For Readily Soluble Nuclides, } \\ \left(I_{o} / I_{0}\right) N^{*} e^{-\lambda t}, & \text { For Low-solubility Nuclides. }\end{cases}
$$

where $l_{0}$ is the peak curie inventory of the nuclide, and

$I$, is the total mass inventory of the nuclide.

Thus the fractional release rate is

$$
f=\frac{1}{Y_{o}} g q
$$

Table IV shows the initial volumes ${ }^{20}$ of brine around a waste package of various types at various potential salt repository locations. It is readily apparent that the type of waste and the type of salt determine the initial volumes of brine around a waste package.

McNulty, Bloom and Raines used a diffusion coefficent derived from the distribution of water around a large brine pocket in a salt mine at Weeks Island Dome, Louisiana. They used a diffusion coefficient of $1.5 \times 10^{-4} \mathrm{~m}^{2} / \mathrm{a}$. As pointed out by the Performance Assessment National Review Group, ${ }^{21}$ this estimat. depends on the assumed start time of the diffusion process, which cannot be measured. 
Tabìe IV. Maximum Expected Brine Volume per Paclesge, $\mathrm{m}^{3}$

\begin{tabular}{|l|c|c|}
\hline Potential Salt Site & $\begin{array}{c}\text { Commercial High-Level } \\
\text { Waste Package }\end{array}$ & $\begin{array}{c}\text { Spent Fuel from PWR } \\
\text { Waste Package }\end{array}$ \\
\hline Dear Smith County & 0.95 & 0.75 \\
Swisher County & 0.96 & 0.77 \\
Davis Canyon & 1.02 & 0.78 \\
Lavendor Canyon & 1.02 & 0.78 \\
Richton Dome & 0.18 & 0.14 \\
C:press Creek Dome & 0.14 & 0.11 \\
Vacherie Dome & 0.18 & 0.14 \\
\hline
\end{tabular}

Figure 4 shows that the calculations by McNulty, Blcom and Raines predict higher release rates than those predicted by the analysis in Section 2. For the results shown in Figure 4, the maximum expected brine volume for the potential site at Deaf Smith County is used, as well as a uranium solubility of $0.001 \mathrm{~g} / \mathrm{m}^{3}$ and an initial inventory of $9.44 \times 10^{5} \mathrm{~g} / \mathrm{MTHM}$ in a $5.5 \mathrm{MTHM}$ waste package. The analysis in Section 2 is more realistic because it is based on a detailed analysis of the ectual transport mechanism. There is no evidence that brine moves through solid salt via the "diffusion-like" process assumed by McNult;, Bloom and Raines.

\section{Conclusion}

We have analysed diffusion of radionuclive near waste packages in a salt repository. According to this analysis, it is unlikely that any low-solubility species wili have difficulty meeting the USNRC release rate requirement at the bare waste/salt interface. For readily soluble species it appears that the metallic container will assist in meeting the USNRC release rate requirement.

\section{References}

1. T. H. Pigford and P. L. Chambré, “Mass Transfer in a Salt Repository," LBL-19918, 1985.

2. T. Brandshaug, Estimate of Consolidation of Crushed Salt Around a Spent Fuel Waste Package. RE/SPEC Report RSI-315, 1987.

3. Y. Hwang, P. L. Chambré, W. W.-L. Lee and T. H. Pigford, "Pressure-Induced Brine Migration into an Open Borehole in a Salt Repasitory," Thans. Am. Nuc. Soc., 55, 133, 1987.

4. Y. Hwang, P. L. Chambre, W. W.-L. Lee and T. H. Pigford, "Pressure-Induced Brine Migration in Consolidated Salt in a Repository," Ttans. Am. Nuc. Soc., 55, 132, 1987.

5. U. S. Nuclear Regulatory Commission, Disposal of High-Level Radioactive Wastes in Geologic Repositories, 10 Code of Federal Regulations 60.I13(a)(1)(ii)(B).

6. T. H. Pigford, "Can Cs-137 be Dismissed Under the NRC Release-Rate Criteron for Geologic Reposito- 


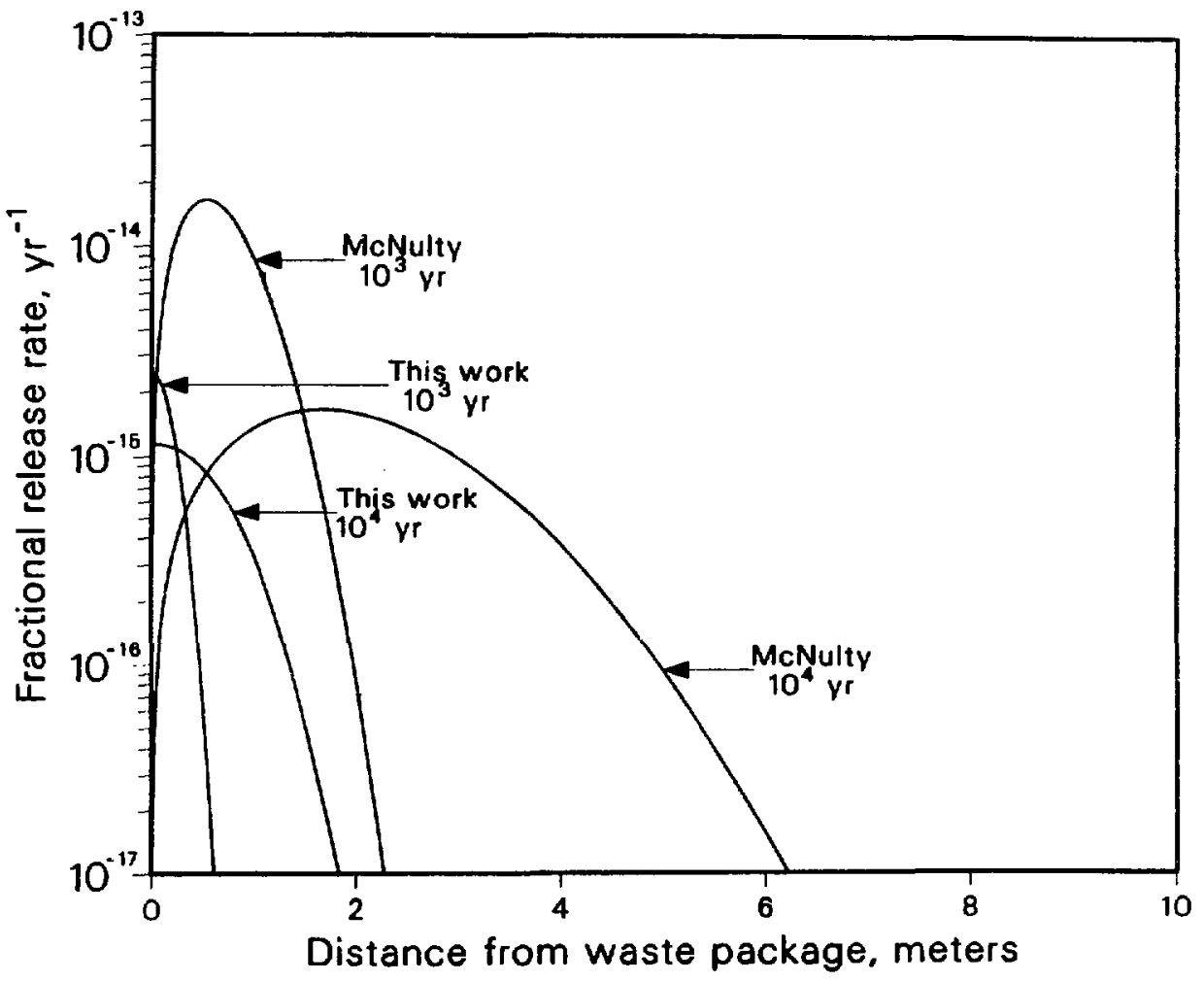

Figure 4. Comparison of Current Analysis with McNulty et al. for U-238 
ries," UCB-NE-4088, July 1986.

7. E. G. McNulty, S. G. Bloom and G. E. Raines, Expected Near-Field Radionuclide Transport for Nuclear Waste Repositories at Potential Salt Sites. BMI/ONWI-670, 1987.

8. U.S. Department of Energy, Environmental Assessment, Deaf Smith County Site, Texas, DOE/RW-0069, 1986.

9. U.S. Department of Energy, Environmental Assessment, Richtor Dome Site, Mississippi, DOE/RW-0072, 1986.

10. U. S. Department of Energy, Environmental Assessment, Davis Canyon Site, Utah, DOE/RW-0071, 1986.

11. C. L. Kim, P. L. Chambré and T. H. Pigford, "Mass-Transfer Limited Release of a Soluble Waste Species," Trans. Am. Nuc. Soc., 52, 80, 1986.

12. P. L. Chambré and T. H. Pigford, "Predictions of Waste Performance in a Geologic Repository," in G. L. McVay (ed.), Scientific Basis for Nuclear Waste Management VII, New York: Elsevier, pp. 985-1008 1983

13. P. L. Chambré, to be published.

14. J. W. Roddy, H. C. Claiborne, R. C. Ashline, P. J. Johuson and B. T. Rhyne, Physical and Decay Characteristics of Commercial LWR Spent Fuel, Report ORNL/TM-9591/V1\&R1, 1986.

15. D. T. NicTigue, "Thermoelastic Response of Fluid-Saturated, Porous Rock," J. Geophy. Res., 91, E9, $9533,1986$.

16. T. H. Pigford, J. O. Blomeke, T. L. Brekke, G. A. Cowan, W. E. Falconer, N. J. Grant, J. R. Johnson, J. M. Matusek, R. R. Parizek, R. L. Pigford, and D. E. White, A Study of the Isolation System for Geologic Disposal of Radioactive Wastes, Washington: National Academy Press, 1983.

17. P. Cloke, personal communication, 1987.

18. E. Browne and R. B. Firestone, Table of Radioactive Isotopes, New York: Wiley, 1986.

19. Letter from R. 1. Browning, Director, Division of Waste Management, U. S. Nuclear Regulatory Commission, to W. Bennett, U. S. Department of Energy, September 10, 1984; also Appendix E of Ref. 21.

20. V. S. McCauley and G. E. Raines, Expected Brine Movement at Potential Nuclear Waste Repository Sites, BMI/ONWI-654, 1987.

21. J. A. Lieberman, S. N. Davis, D. R. F. Harleman, R. L. Keeney, D. C. Kocher, D. Langmuir, R. B. Lyon, W. W. Owen, T. H. Pigford and W. W.L. Lee, Performance Assessment National Review Group, Weston Report RFW-CRWM-85-01, 1985, 114 pages. 